\title{
Cell cycle genes and ovarian cancer susceptibility: a tagSNP analysis
}

\section{JM Cunningham*,1, RA Vierkant ${ }^{2}$, TA Sellers ${ }^{3}$, C Phelan ${ }^{3}$, DN Rider ${ }^{2}$, M Liebow $^{4}$, J Schildkraut ${ }^{5}$, A Berchuck ${ }^{6}$, FJ Couch', X Wang', BL Fridley', Ovarian Cancer Association Consortium, A Gentry-Maharaj', U Menon', E Hogdall $^{8}$, S Kjaer ${ }^{8,9}$, A Whittemore ${ }^{10}$, R DiCioccio ${ }^{11}$, H Song ${ }^{12}$, SA Gayther ${ }^{7}$, SJ Ramus ${ }^{7}$, PDP Pharaoh ${ }^{12}$ and EL Goode ${ }^{2}$}

'Department of Laboratory Medicine and Pathology, Mayo Clinic College of Medicine, 200 First Street SW, Rochester, MN 55905, USA; ${ }^{2}$ Department of Health Sciences Research, Mayo Clinic College of Medicine, 200 First Street SW, Rochester, MN 55905, USA; ${ }^{3}$ Department of Epidemiology and Genetics, H. Lee Moffitt Cancer Center and Research Institute, 12902 Magnolia Drive, Tampa, FL 336 I2, USA; ${ }^{4}$ Department of Internal Medicine, Mayo Clinic College of Medicine, 200 First Street SW, Rochester, MN 55905, USA; ${ }^{5}$ Department of Community and Family Medicine, Duke University Medical Center, Durham, NC 27710, USA; ${ }^{6}$ Department of Obstetrics and Gynaecology, Duke University Medical Center, Durham, NC 277I 0, USA;

${ }^{7}$ Department of Gynaecological Oncology, UCL EGA Institute for Women's Health, University College London, 46 Cleveland St., London, WIT 4JF, UK; ${ }^{8}$ Department of Viruses, Hormones, and Cancer, Institute of Cancer Epidemiology, Danish Cancer Society, Righospitalet Strandboulevarden 49,

Copenhagen, DK-2100, Denmark; ${ }^{9}$ Department of Gynaecology and Obstetrics, Gynaecologic Clinic, Juliane Marie Center, Rigshospitalet, University of Copenhagen, Copenhagen, CR-UK, Denmark; ${ }^{10}$ Department of Health Research and Policy, Stanford University School of Medicine, Palo Alto, CA 94305, USA; "'Department of Cancer Genetics, Roswell Park Cancer Institute, Buffalo, New York 14263, USA; '2 Department of Oncology, Cancer Research United Kingdom and Strangeways Research Laboratory, Cambridge University, Worts Causeway, CBI8RN, Cambridge, UK

BACKGROUND: Dysregulation of the cell cycle is a hallmark of many cancers including ovarian cancer, a leading cause of gynaecologic cancer mortality worldwide.

METHODS: We examined single nucleotide polymorphisms (SNPs) $(n=288)$ from 39 cell cycle regulation genes, including cyclins, cyclin-dependent kinases (CDKs) and CDK inhibitors, in a two-stage study. White, non-Hispanic cases $(n=829)$ and ovarian cancer-free controls $(n=94 I)$ were genotyped using an Illumina assay.

RESULTS: Eleven variants in nine genes (ABL1, CCNB2, CDKNIA, CCND3, E2F2, CDK2, E2F3, CDC2, and CDK7) were associated with risk of ovarian cancer in at least one genetic model. Seven SNPs were then assessed in four additional studies with 1689 cases and 3398 controls. Association between risk of ovarian cancer and ABLI rs2855/92 found in the original population [odds ratio, $\mathrm{OR}_{\mathrm{BB} \text { vs } \mathrm{AA}} 2.8 \mathrm{I}(\mathrm{I} .29-6.09), P=0.0 \mathrm{I}$ ] was also observed in a replication population, and the association remained suggestive in the combined analysis $\left[O R_{B B}\right.$ vs AA $\left.1.59(1.08-2.34), P=0.02\right]$. No other SNP associations remained suggestive in the replication populations.

CONCLUSION: ABLI has been implicated in multiple processes including cell division, cell adhesion and cellular stress response. These results suggest that characterization of the function of genetic variation in this gene in other ovarian cancer populations is warranted. British Journal of Cancer (2009) I 0 I, |46|-|468. doi:I0.1038/sj.bjc.6605284 www.bjcancer.com

Published online 8 September 2009

(c) 2009 Cancer Research UK

Keywords: ovarian cancer; cell cycle; tag SNPs genes

Ovarian cancer is the seventh most common cancer and the fourth leading cause of cancer death in women worldwide (Parkin et al, 2005). With the highest mortality of all gynaecological malignancies, 15520 deaths were estimated in the US in 2008 (American Cancer Society, 2008). The pathogenesis and progression of ovarian cancer is not well understood, which contributes to its poor survival, along with difficulties in early detection among asymptomatic women. Modifiable risk factors, which are few, include oral contraceptives, family history and age at menarche. Known genetic risk factors are restricted to mutations inherited in the high risk, high penetrant genes (e.g. BRCA1/2 and DNA

\footnotetext{
*Correspondence: Dr JM Cunningham;

E-mail: cunningham.julie@mayo.edu

Received II June 2009; revised 29 July 2009; accepted 31 July 2009; published online 8 September 2009
}

mismatch repair genes), which are rare in the general population and estimated to account for no greater than $10-15 \%$ of ovarian cancer (Chen et al, 2006; Lancaster et al, 2007). Owing to a consensus that genetic factors have a function in susceptibility to ovarian cancer, studies targeting specific pathways in ovarian cancer case-control studies have emerged (Dicioccio et al, 2004; Auranen et al, 2005; Beesley et al, 2007; Song et al, 2007; Mann et al, 2008; Pearce et al, 2008; Quaye et al, 2008) and some report nominally significant associations with ovarian cancer risk (Buller et al, 1997; Berchuck et al, 2004; Dicioccio et al, 2004; Kelemen et al, 2008; Pearce et al, 2008; Sellers et al, 2008).

Dysregulation of the cell cycle is a hallmark of many cancers (Pharoah et al, 2007; Butt et al, 2008; Nam and Kim, 2008) and control and timing of the cell cycle involves checkpoints and regulatory pathways that ensure the fidelity of DNA replication 
Table I Cell cycle related genes

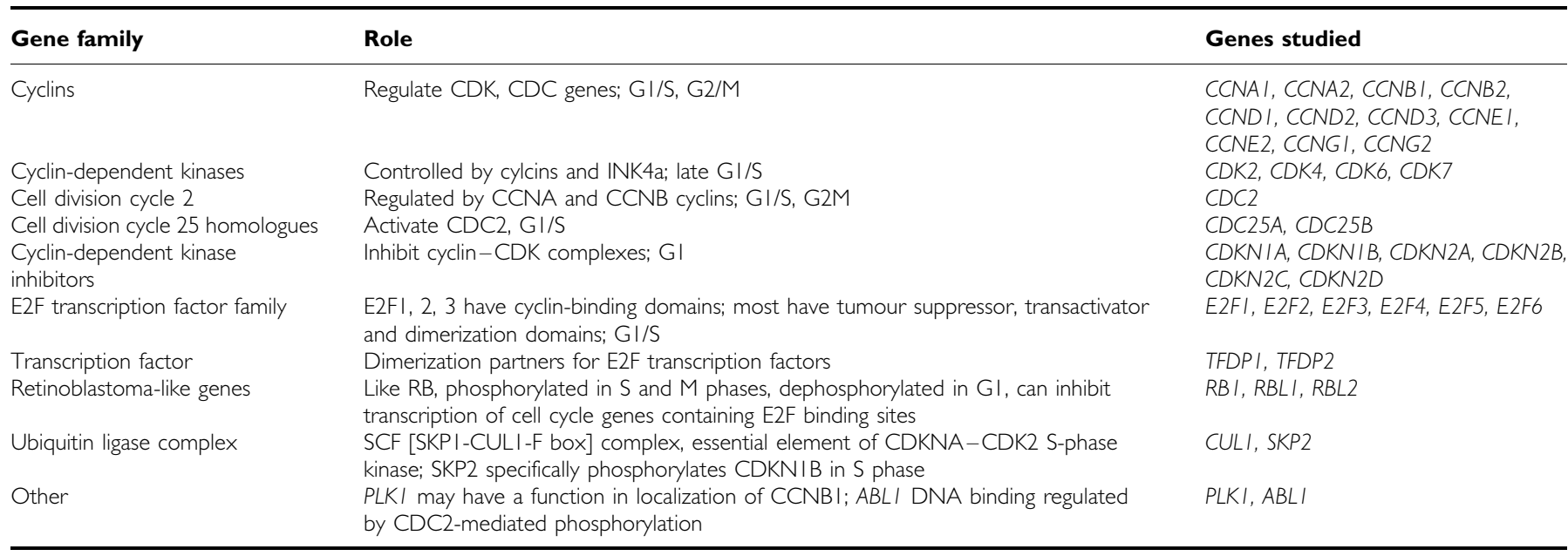

and chromosome segregation (Elledge, 1996). These processes involve a large collection of key molecules, which are excellent candidates for ovarian cancer susceptibility variants. These include the cyclins (CCNA1, CCNA2, CCNB1, CCNB2, CCND1, CCND2, CCND3, CCNE1, CCNE2, CCNG1, CCNG2), cyclin-dependent kinases (CDKS: $C D K 2, C D K 4, C D K 6, C D K 7, C D C 2$ ), $C D K$ inhibitors (CDKN1A, CDKN1B, CDKN2A, CDKN2B, CDKN2C, CDKN2D) and CDC2 regulators $(C D C 25 A, C D C 25 B)$. The catalytic subunit of CDKs is activated by one of many activating subunits, the cyclins. Cyclin levels oscillate during the cell cycle, and cyclin-CDK complexes finely regulate progression through the cell cycle. Inhibitors of CDK promote cell cycle arrest and may affect response to mitogenic stimuli. In addition to the cyclins, CDKs and CDK inhibitors, the E2 family of transcription factors is a critical element as well as the E2F family's dimerization partners TFDP1, TFDP2, CUL1 and SKP2, which are involved in the SCF ubiquitin ligase complex. In addition, $\mathrm{Rb}$ (and two $\mathrm{Rb}$-like genes) regulates progression of cells from $\mathrm{G} 1$ to $\mathrm{S}$ to $\mathrm{G} 2$ phases. CCND, CCNE and E2F are over-expressed in a variety of cancer, including ovarian cancer ( $\mathrm{D}^{\prime}$ Andrilli et al, 2004), and data emanating from an immunohistochemical study of ovarian cancer (Hashiguchi et al, 2004) reveals alteration of G2 in ovarian cancer specimens. The SCF ubiquitin ligases are well-characterized mammalian cullin RING ubiquitin ligases (Frescas and Pagano, 2008), and this complex is an essential element in the CDKNA-CDK2 S phase. SKP2 activates CDK2 and CDK1 by directing the degradation of CDKN1 (p27) and CDKN1B (p21). SKP2 is also known to target tumour suppressor proteins $\mathrm{p} 21$ and $\mathrm{CDKN} 1 \mathrm{C}$, resulting in protein degradation (Frescas and Pagano, 2008). Activation and inactivation of CDKs is an additional crucial process, and dysregulation may be involved in cell transformation. Other important kinases include ABL1, a non-tyrosine kinase, that may regulate the $\mathrm{CDC} 2$ kinase (Lin et al, 2004), and PLK1, a cell cycle regulated kinase (Yuan et al, 2002).

As cell cycle abnormalities have been observed in ovarian cancer (Milde-Langosch and Riethdorf, 2003; De Meyer et al, 2009), we hypothesized that common genetic variation in genes altering the functionality of the molecules may influence the ovarian carcinogenic process. An earlier study of 13 genes (88 informative single nucleotide polymorphisms, SNPs) involved in regulation of the G1 -S phase of the cell cycle (CCNDA, CCND2, CCND3, CCNE1, $C D K 2, C D K 4, C D K 6, C D K N 1 A, C D K N 1 B, C D K N 2 A, C D K N 2 B$, $C D K N 2 C$ and $C D K N 2 D)$ found nominally significant associations between SNPs in CDKN2A and CDKN1B [rs3731257 homozygous minor $v s$ homozygous major odds ratio, $\mathrm{OR}_{\mathrm{BB}}$ ss $\mathrm{AA}, 0.87(95 \%$ confidence interval, 95\% CI, $0.73-1.03) P$-value $=0.021$; rs2066827
$\mathrm{OR}_{\mathrm{BB} \text { vs AA }} 0.79$ (0.66-0.95) P-value $\left.=0.04\right]$ (Gayther et al, 2007). In addition, a combined analyses of 6 studies and 12 genes including imputed genotypes found evidence of association with selected SNPs in CDKN2A,CCND1,CDK2 and CCNE1, but not in CDKN2C, CDKN1A, CCND3, CCND2,CDKN1B,CDK4, RB1, $C D K N 2 D$ or $C D K N 2 B$ (Goode et al, 2009) Here, we report on a more comprehensive two-stage analysis of the association of ovarian cancer risk at 39 genes (288 SNPs) involved in G1/S and G2/M phases of the cell cycle and transcription- and ubiquitinmediated degradation (Table 1).

\section{MATERIALS AND METHODS}

This study used a two-stage approach: a discovery set comprised of two populations and a replication set comprised of four additional populations. SNPs with suggestive statistical significance in the discovery set were carried through to the replication set to validate the results. Details for these sets and SNP selection are provided below.

\section{Discovery set}

The discovery population comprised of 2051 women participating in an ongoing ovarian cancer case-control study at the Mayo Clinic (MAY) and Duke University (NCO) recruited between June 1999 and March 2006, as described earlier (Kelemen et al, 2008; Sellers et al, 2008). Study protocols were approved by the Institutional Review Boards at both institutions, and study participants provided written informed consent. Cases were women for whom a diagnosis of histologically confirmed primary epithelial ovarian cancer was ascertained within 1 year of consent. Information on known and suspected ovarian cancer risk factors was collected by in-person interviews, including race/ethnicity, menstrual and reproductive history, use of exogenous hormones, medical and surgical history, tobacco use levels, education level, height and weight 1 year before interview and family history of breast and ovarian cancer in first- or second-degree relatives. DNA was extracted from fresh peripheral blood using the Gentra AutoPure LS Puregene salting out methodology (Gentra Inc, Minneapolis, MN, USA). For NCO samples with limited DNA available, WGA was performed using the REPLI-G protocol (Qiagen) with $200 \mathrm{ng}$ genomic DNA as input yielding high molecular weight DNA and reproducible genotype data (Cunningham et al, 2008). Of the 2051 eligible participants, 1967 (95.6\%) 
were successfully genotyped, including 1770 white, non-Hispanic participants used in this report (829 cases and 941 controls).

\section{Replication sets}

Four case-control study populations were included in a replication analysis: the SEARCH ovarian cancer study from East Anglia, United Kingdom (SEA), the MALOVA cancer study from Denmark (MAL), the GEOCS study from Stanford University in Palo Alto, CA (STA) and the UK OPS Study from the United Kingdom (UKO). The SEA study (696 cases/1227 controls) included invasive epithelial ovarian cancer cases collected from the East Anglian and West Midlands cancer registries, and controls randomly selected from European Prospective Investigation into Cancer and Nutrition (EPIC) - Norfolk cohort study. The MAL study (439 cases/ 1215 controls) contained invasive ovarian cancer cases and population controls randomly drawn from a defined study area in Denmark. The STA study (285 cases/364 controls) ascertained participants from six counties in northern California including invasive ovarian cancer cases and age-matched controls obtained using random-digit dialling. The UKO study (269 cases/592 controls) drew cases from 10 gynaecologic oncology National Health Service Centers and apparently healthy controls from the UK Collaborating Trial of Ovarian Cancer Screening (UKCTOCS). Additional replication study participant details are provided elsewhere (Gayther et al, 2007; Ramus et al, 2008). Only white, non-Hispanic participants were included.

\section{Discovery SNP selection and genotyping}

SNP selection for the discovery set involved identifying tagSNPs for the 39 genes (Table 1; Supplemental Table 1). To accomplish this, genotype data from the HapMap consortium http://hapmap. org, Seattle SNPs http://pga.mbt.washington.edu, Perlegen Sciences http://genome.perlegen.com and Panel 2 of the National Institute for Environmental Health Sciences http://egp.gs.washingon. edu were analysed with ldSelect (Carlson et al, 2004) to bin SNPs with European American MAF $>0.05$ at a pairwise linkage disequilibrium (LD) threshold of $r^{2} \geqslant 0.8$. The region for each gene included $5 \mathrm{~kb}$ upstream and downstream. Using these data, 288 tagSNPs and putative functional SNPs (non-synonymous coding SNPs and SNPs altering splicing) for the 39 cell cycle genes were included in one of two genotyping panels consisting of 2688 SNPs as part of a larger genotyping effort (Supplementary Tables S1 and S2). Details about the Illumina GoldenGate genotyping have been reported earlier (Cunningham et al, 2008; Kelemen et al, 2008; Sellers et al, 2008). Illumina design scores were $>0.6$ for $94.9 \%$ of the SNPs. Quality control data for the 288 cell cycle SNPs are provided in Supplementary Table S2. SNP call rates were $>0.95$ and replicate concordance was $>0.99$.

\section{Replication SNP selection and genotyping}

SNPs with log-additive $P$-values $<0.05$ were considered for replication. In addition, for SNPs not selected under the logadditive model, but with a suggestion of association in either dominant or recessive models, a more stringent threshold was applied $(P$-value $\leqslant 0.03)$ for inclusion in the replication (statistical methods described below). One of these SNPs (CDK2 rs2069414) could not be genotyped using TaqMan, the replication platform, and one of these SNPs (CCND3 rs3218086) was replaced by rs3218092, which was in LD $\left(r^{2}=0.95\right)$ with $r s 3218086$ and had earlier been genotyped. Thus, six replication SNPs were genotyped at the Strangeways Research Laboratory using TaqMan designed assays, following the manufacturer's recommended protocols; rs3218092 had been similarly assayed (Gayther et al, 2007). Each assay used $10 \mathrm{ng}$ DNA in a $5 \mu \mathrm{l}$ reaction volume with TaqMan universal PCR Master Mix (Applied Biosystems, Warrington, UK); primer and probe sequences, as well as assay conditions, are available on request. TaqMan Allele Discrimination Sequence Detection software (Applied Biosystems) was used to determine genotype calls. SNP call rates were $>0.95$ and replicate concordance was $>0.99$.

\section{Statistical analyses}

Discovery set participants were examined initially and restricted to white, non-Hispanic participants. Departures from Hardy-Weinberg equilibrium (HWE) for each SNP were examined using Pearson goodness-of-fit $\chi^{2}$ tests or, for SNPs with minor allele frequencies $<5 \%$, exact tests (Weir, 1996). One SNP (rs12527393 in E2F3) had HWE $P$-value $<0.001$ among controls and was excluded from analysis. Pairwise LD was estimated using $r^{2}$ statistics and graphically displayed using the Haploview v14.1 (Barrett et al, 2005). Unconditional logistic regression analysis was used to estimate OR and 95\% CI for risk of ovarian cancer associated with each SNP. Primary tests of association assumed a log-additive (multiplicative) genotypic effect, equivalent to the Armitage test for trend. We also performed separate comparisons of women with one copy $\left(\mathrm{OR}_{\mathrm{AB}} v_{\mathrm{AA}}\right)$ and two copies $\left(\mathrm{OR}_{\mathrm{BB}} v_{s \mathrm{AA}}\right)$ of the minor allele to women with no copies (reference). Secondary analyses examined dominant and recessive SNP effects. All analyses were adjusted for the design variables of age and geographic region, as well as the following potential confounding variables found to be associated with ovarian cancer risk in the discovery set $(P$-value $<0.05)$ : body mass index, postmenopausal hormone use, oral contraceptive use, parity and age at first birth.

Replication association testing was similarly carried out for each SNP using unconditional logistic regression analyses as described above. Associations were examined by site, as well as combined across sites, adjusting for age. Analyses were conducted including and excluding the discovery set participants, adjusting for age and study site. Two sets of $P$-values were calculated for the replication set: one based on the simple comparison-wise error rate and one accounting for the number of replication tests using a Bonferroni correction.

\section{Results}

Distributions of risk factor information for the discovery set have been described earlier (Sellers et al, 2005; Kelemen et al, 2008). Generally, case-control differences were similar across both discovery sites: overall, cases tended to be more obese, have lower parity, reported a greater family history of ovarian cancer and were more likely to have used hormone therapy (NCO site) or oral contraceptives (MAY site). Of the 288 SNPs attempted, 269 (93.4\%) passed quality control and were included in the analysis. Eleven variants in nine genes showing significance at $P$-value $<0.05$ for adjusted (multivariate) analyses using log-additive (ordinal), recessive or dominant models are shown in Table 2. Assuming a log-additive model, variants in five genes revealed significant associations ( $P$-value <0.05): $A B L 1$ rs2855192, CDKN1A rs776246, CCND3 rs3218086, $C D K 2$ rs2069414 and E2F3 rs7760528. SNPs in two of these genes ( $A B L 1$ and E2F3) revealed additional evidence of a recessive effect, whereas SNPs in CDKN1A, CCND3 and CDK2 revealed additional evidence of a dominant association (Table 2). Although our analysis used the log-additive model as the primary analysis, there were two additional SNPs, rs2448343 in CDC2 and rs12656449 in CDK7, with non-significant $P$-values in the log-additive model, but significant $P$-values using a recessive model: OR 0.67 (95\% CI $0.50-0.89$ ), $P=0.006$ and OR 2.91 (95\% CI $1.11-8.05) \quad P=0.03$, respectively. CCNB2 rs1486878 (OR 1.50, 95\% CI 1.05-2.15) also suggested association only with a recessive model $(P=0.04)$.

Eight of the 11 significant SNPs were chosen for replication. These included ABL1 rs2855192, CDKN1A rs7767246, CCND3 rs3218086 (which was substituted with rs3218092, $r^{2}-0.95$ ), E2F3 
Table 2 Discovery set: cell cycle SNPs and ovarian cancer risk $(P<0.05)$

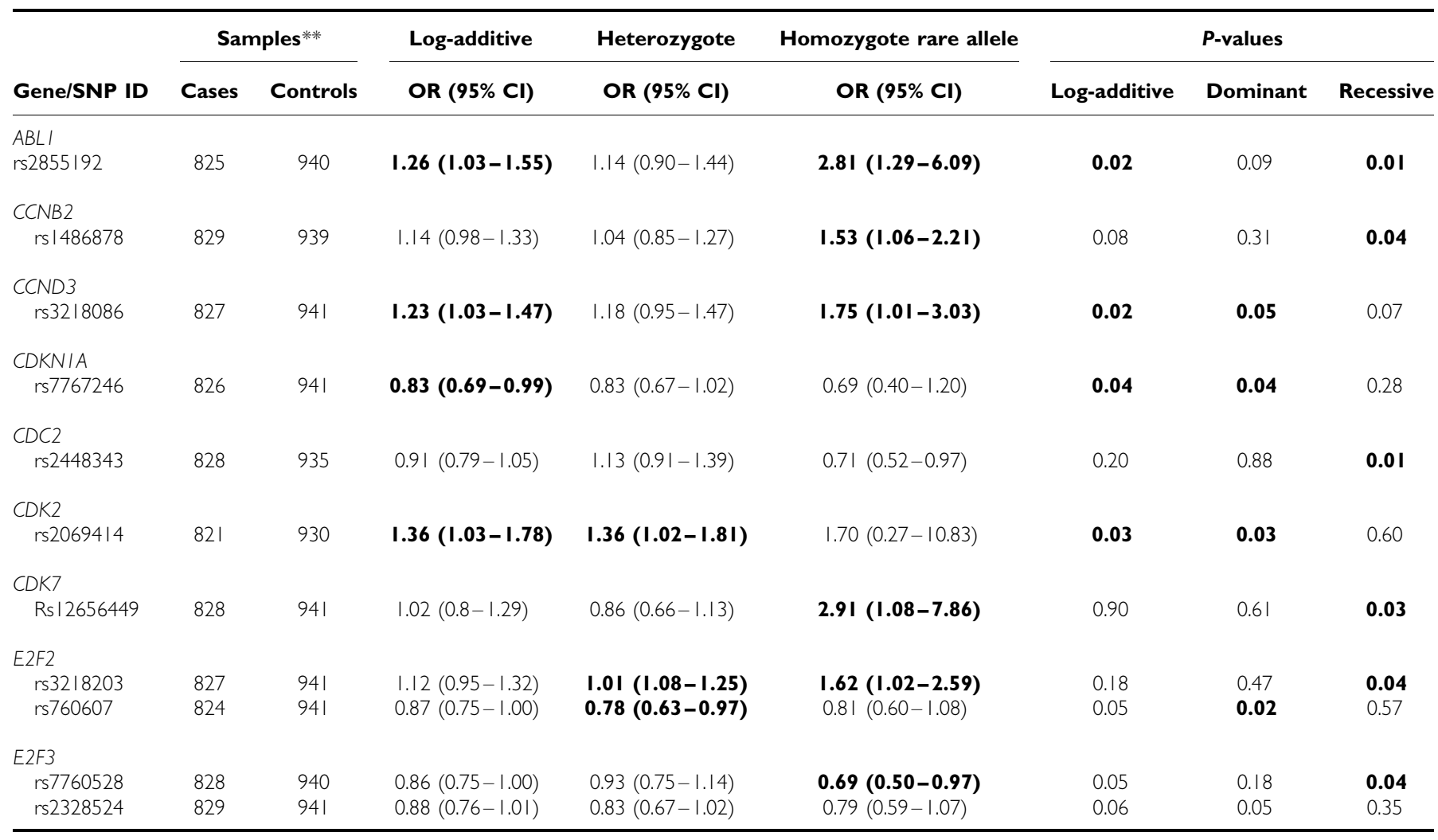

Multivariate logistic hormone replacement therapy, parity and body mass index; $P$-values $<0.05$ are in bold type, as are Cls that exclude I.0.

rs7760528 and CDK2 rs2069414 (the latter of which was excluded because of lack of TaqMan assay conversion) based on the logadditive model $P$-value $<0.05, E 2 F 2$ rs760607 based on dominant model, $P$-value of 0.02 , and $C D C 2$ rs2448343 and $C D K 7$ rs 12656449 based on recessive model, $P$-value of 0.01 and 0.03 , respectively, in the discovery set analysis (Table 2). Table 3 provides results for site-specific and combined replication analyses. For one SNP, rs 2855192 in $A B L 1$, the results were similar to those obtained in the discovery sample set, in one of the four sites (STA), with a log-additive increase in risk $(P$-value $=0.03$, Table 3 ; Figure 1$)$ and also consistent with a recessive effect. Combined analysis of all sites revealed a suggestion of a recessive association (OR for homozygous minor allele genotypes compared with homozygous major allele, $\mathrm{OR}_{\mathrm{BB}}$ vs $\mathrm{AA} 1.59,95 \%$ CI 1.08-2.34, $P$-value $=0.02$ ). Excluding the discovery sites, this association was attenuated (OR 1.40, 95\% CI $0.89-2.19, \quad P$-value $=0.14) \quad($ Table 3$) . \quad E 2 F 3$ rs776052 was associated with ovarian cancer risk in one replication population (UKO), but did not remain significant in the combined analysis. CDKN1A rs776246 and CDC2 rs2448343 were associated with risk in one population each (MAL and OPS, respectively), but the risk estimates were in the opposite direction to that found in the discovery set and not considered replications. CDC2 rs 2448343 was significantly associated using all datasets assuming a recessive model only. None of the replication results remained statistically significant after correction for multiple testing (data not shown). For SNPs in $C C N D 3, C D K 7, E 2 F 2$ and $E 2 F 3$, no replication of the initial result was seen in any of the replication sites, and the combined analysis did not reveal any significant findings (Table 3; Figure 1).

\section{Discussion}

This study used a two-stage approach to assess the contribution of inherited variation in 39 cell cycle genes to the risk of epithelial ovarian cancer and found some evidence of association at $A B L 1$ rs2855192. Cell cycle dysregulation is a hallmark of the malignant state, and the function of genetic variation in cell cycle genes, including in ovarian cancer, has been reported in a number of studies (Gayther et al, 2007; Goode et al, 2009); this study extends the prior findings by the inclusion of an additional 26 and 28 additional genes, respectively. In the discovery set, SNPs in several genes were found to be associated with the risk of ovarian cancer; of these, five genes ( $A B L 1, C C N D 3, C D K N 1 A, E 2 F 3$ and $C D K 2)$ were significant in log-additive models ( $P$-value $<0.05)$. This study also found four additional variants in CCNB2, CDC2, CDK7 and E2F2 (rs3328203) to be significant assuming a recessive model only. One additional variant in E2F2 (rs76067) was found to be associated assuming a dominant model, but not in the log-additive model. Replication testing of seven SNPs revealed one SNP in $A B L 1$ to have an association in one of the four replication populations assessed (also from the US) and was significant overall with a recessive model. However, once adjustments for multiple comparisons were made, no significant association was noted for any variant.

ABL1 is a ubiquitously expressed, non-tyrosine kinase, encoding both cytoplasmic and nuclear kinases (Preyer et al, 2007). The $A B L 1$ gene is expressed as either a 6 or $7 \mathrm{~kb}$ mRNA transcript, with alternatively spliced first exons spliced to exons $2-11$. ABL1 has been implicated in processes of cell differentiation, cell division, cell adhesion and cellular stress response (Wang, 1993; Kharbanda et al, 1995; Lewis et al, 1996; Barila and Superti-Furga, 1998). A $t(9 ; 22)$ translocation, which results in the head-to-tail fusion of the $B C R$ and $A B L 1$ genes, is present in many cases of chronic myelogeneous leukaemia (De Keersmaecker and Cools, 2006). The DNA-binding activity of ABL1 tyrosine kinase is regulated by CDC2-mediated phosphorylation, suggesting a cell cycle function for ABL1 (Welch and Wang, 1993). The tyrosine kinase activity of nuclear ABL1 is regulated in the cell cycle through a specific 
Table 3 Discovery and replication sets: cell cycle SNPs and ovarian cancer risk

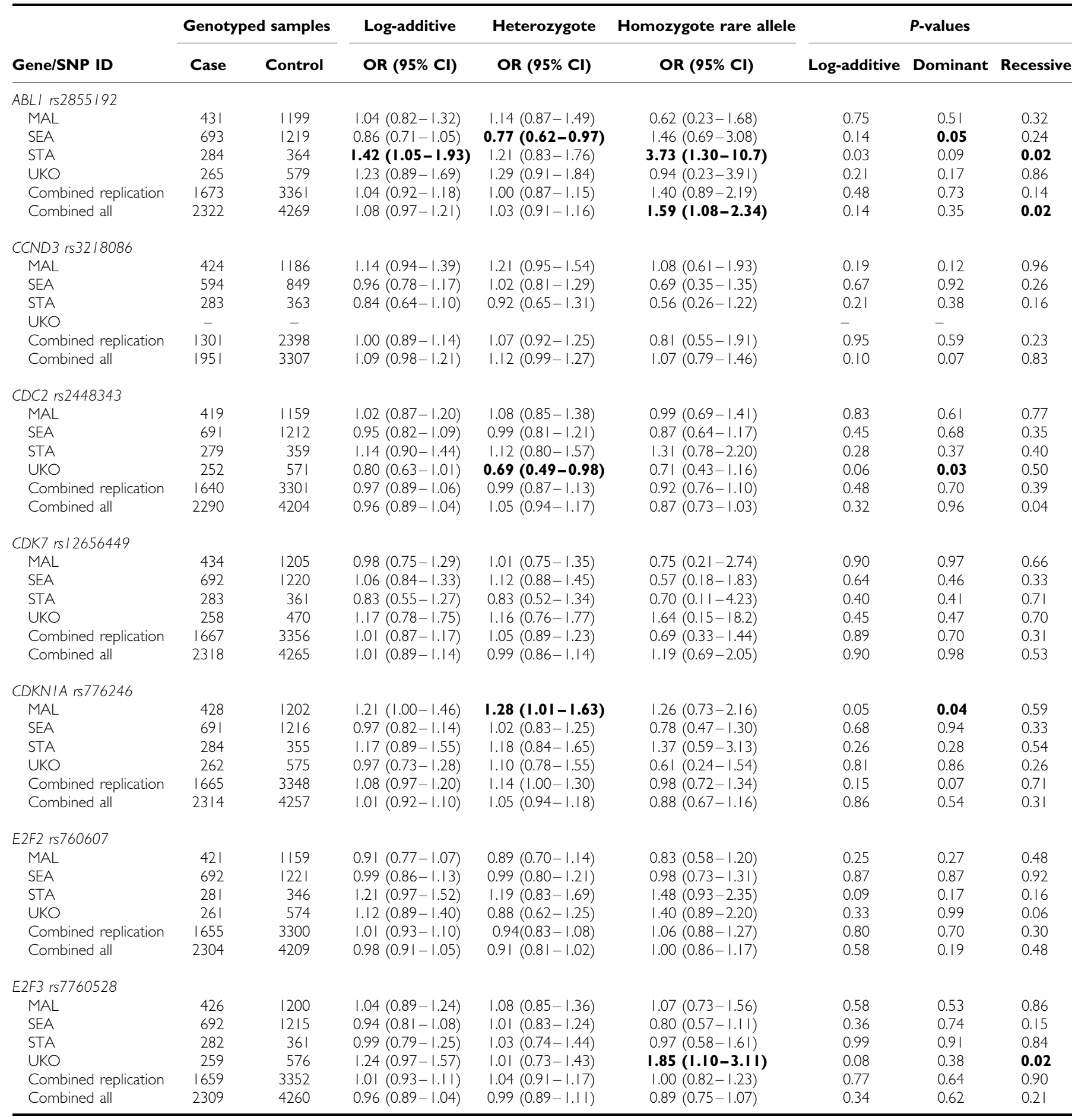

Logistic regression analysis adjusting for age and, for combined results, study site; $P$-values $\leqslant 0.05$ and $C l$ that exclude 1.0 are in bold type; combined all indicates discovery plus replication sets; CCND3 rs32189092 was substituted for CCND3 rs3218086 in replication sets.

interaction with $\mathrm{Rb}$ (Welch and Wang, 1993). When in the cytoplasm, ABL1 responds to growth factor and adhesion signals to regulate F-actin dynamics (Woodring et al, 2003). As acquired resistance to imatinib is associated with mutations in the kinase domain of BCR-ABL that interferes with drug binding, it may be possible that a coding SNP in ABL1 modulates the imatinib response (Crossman et al, 2005). The associated SNP, rs2855192, is in intron 1 and the functional aspects are unknown; this SNP was a tagSNP, but did not tag any other SNPs (i.e. it was in a singleton bin with $r^{2}<0.8$ with other HapMap SNPs). ABL1 was included in this study because of its function in cell cycle function; however, the cytoplasmic form of ABL1 may have a function in cell adhesion in addition to DNA binding when localized to the nucleus.

In an earlier study, variants in $C D K N 1 B$ and $C D K N A 2 / 2 B$ were found to be associated with ovarian cancer risk in a combined analysis of 3601 cases and 5705 controls (Gayther et al, 2007). In this study, no variant in either of these genes was significant in the 


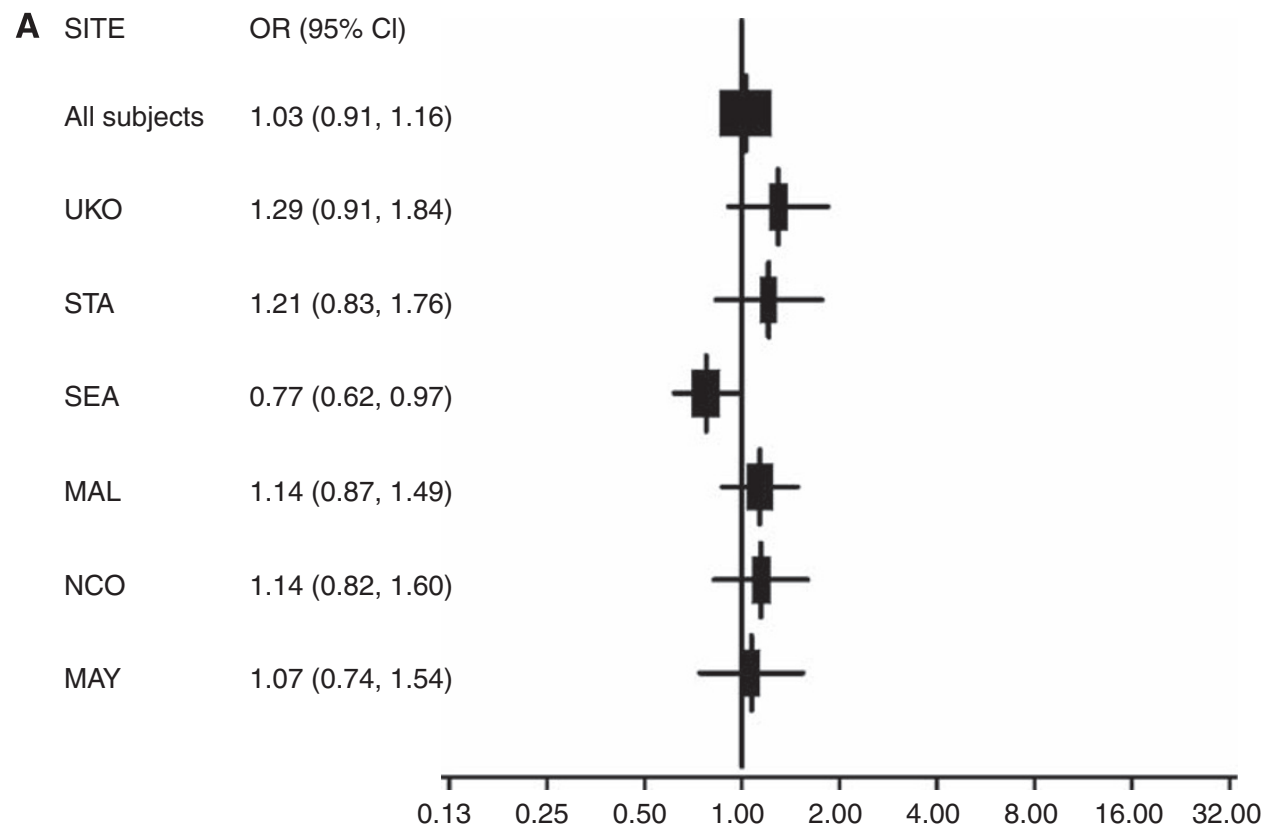

B SITE OR $(95 \% \mathrm{Cl})$

All subjects

$1.59(1.08,2.34)$

UKO

$0.94(0.23,3.9)$

STA

$3.73(1.30,10.71)$

SEA

$1.46(0.69,3.08)$

MAL

$0.62(0.23,1.68)$

NCO

$1.38(0.49,3.88)$

MAY

$1.07(0.74,1.54)$

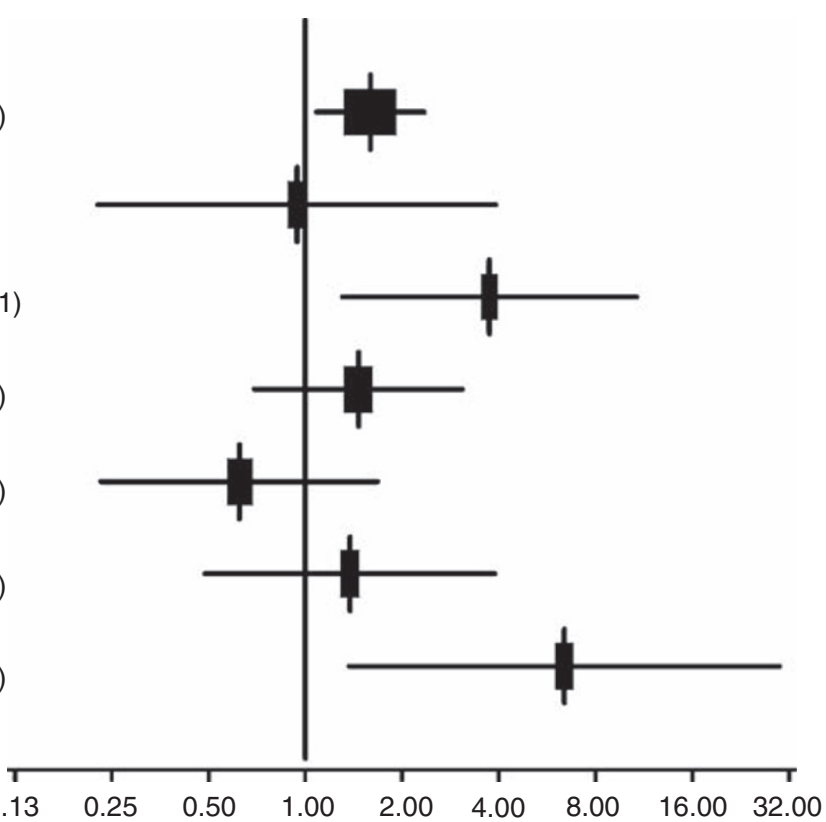

$$
1.07(0.74,1.54)
$$

Figure I Study-specific and combined OR and 95\% Cl for ABL I rs2855 I92. Analyses of all subjects adjusted for age and study site; study-specific analyses adjust only for age. (A) Heterozygous vs homozygous major allele participants ( $O R_{A B}$ vs $\left.A A\right)$. (B) Homozygous minor allele vs homozygous major participants $\left(O R_{B B}\right.$ vs $\left.A A\right)$.

discovery set (Supplementary Table S2) and so were not carried forward to the replication phase. In another study using imputed genotypes, based on data from five independent ovarian cancer studies (Goode et al, 2009), the signal observed for CDNKN1A in the MAY + NCO dataset was not supported by imputation of genotypes in the other four studies, consistent with the replication data in this report. For rs2069391 in CDK2 variant, which could not be genotyped in the replication set in this study (discovery set logadditive OR 1.36, CI 1.03-1.78), imputation revealed a signal in the earlier combined analysis (log-additive OR 1.21, CI 1.01-2.09), which included five of the six populations in this study (Goode et al, 2009).

A strength of this study was its comprehensive nature in terms of the number of genes and number of tagSNPs and inclusion of putatively functional SNPs. Owing to a large number of tests (269 SNPs $\times 3$ genetic modes of inheritance), caution in interpreting the data is warranted; no adjustment was made for multiple testing because of a lack of complete independence of tests. An additional strength of this study is the inclusion of four replication populations, which improves power (Ioannidis et al, 2001; Morgan et al, 2007), although replication genotyping of only the top $2 \%$ of SNPs limited the power of our two-stage approach. In recent metaanalyses and pooled analyses 161 cancer genetic association studies (Dong et al, 2008), close to one-third of all associations were reported to be statistically significant and many of the false positive associations arose from small studies with multiple subset analyses. Therefore, we consider this analysis a preliminary screen of the cell cycle pathway and one which indicates modest 
evidence for association with disease risk for only one gene, $A B L 1$. Additional examination of $A B L 1$ rs2855192, and including other SNPs with suggestive discovery set results, is warranted in additional studies within the ovarian cancer consortium (Ramus et al, 2008).

\section{ACKNOWLEDGEMENTS}

Profound thanks are expressed for the study participants contributing to the project. We are also grateful to the family and friends

\section{REFERENCES}

American Cancer Society (2008) Amercian Cancer Society: Cancer Facts and Figures Estimated New Cases and Deaths by Sex, US 2008. In www.cancer.org/downloads/STT/2008CAFFfinalsecured.pdf

Auranen A, Song H, Waterfall C, Dicioccio RA, Kuschel B, Kjaer SK, Hogdall E, Hogdall C, Stratton J, Whittemore AS, Easton DF, Ponder BA, Novik KL, Dunning AM, Gayther S, Pharoah PD (2005) Polymorphisms in DNA repair genes and epithelial ovarian cancer risk. Int J Cancer 117: $611-618$

Barila D, Superti-Furga G (1998) An intramolecular SH3-domain interaction regulates c-Abl activity. Nat Genet 18: $280-282$

Barrett JC, Fry B, Maller J, Daly MJ (2005) Haploview: analysis and visualization of LD and haplotype maps. Bioinformatics 21: 263-265

Beesley J, Jordan SJ, Spurdle AB, Song H, Ramus SJ, Kjaer SK, Hogdall E, DiCioccio RA, McGuire V, Whittemore AS, Gayther SA, Pharoah PD, Webb PM, Chenevix-Trench G (2007) Association between singlenucleotide polymorphisms in hormone metabolism and DNA repair genes and epithelial ovarian cancer: results from two Australian studies and an additional validation set. Cancer Epidemiol Biomarkers Prev 16: $2557-2565$

Berchuck A, Schildkraut JM, Wenham RM, Calingaert B, Ali S, Henriott A, Halabi S, Rodriguez GC, Gertig D, Purdie DM, Kelemen L, Spurdle AB, Marks J, Chenevix-Trench G (2004) Progesterone receptor promoter $+331 \mathrm{~A}$ polymorphism is associated with a reduced risk of endometrioid and clear cell ovarian cancers. Cancer Epidemiol Biomarkers Prev 13: $2141-2147$

Buller RE, Sood A, Fullenkamp C, Sorosky J, Powills K, Anderson B (1997) The influence of the p53 codon 72 polymorphism on ovarian carcinogenesis and prognosis. Cancer Gene Ther 4: 239-245

Butt AJ, Caldon CE, McNeil CM, Swarbrick A, Musgrove EA, Sutherland RL (2008) Cell cycle machinery: links with genesis and treatment of breast cancer. Adv Exp Med Biol 630: 189-205

Carlson CS, Eberle MA, Rieder MJ, Yi Q, Kruglyak L, Nickerson DA (2004) Selecting a maximally informative set of single-nucleotide polymorphisms for association analyses using linkage disequilibrium. Am J Hum Genet 74: $106-120$

Chen S, Iversen ES, Friebel T, Finkelstein D, Weber BL, Eisen A, Peterson LE, Schildkraut JM, Isaacs C, Peshkin BN, Corio C, Leondaridis L, Tomlinson G, Dutson D, Kerber R, Amos CI, Strong LC, Berry DA, Euhus DM, Parmigiani G (2006) Characterization of BRCA1 and BRCA2 mutations in a large United States sample. J Clin Oncol 24: 863-871

Crossman LC, O'Hare T, Lange T, Willis SG, Stoffregen EP, Corbin AS, $\mathrm{O}^{\prime}$ Brien SG, Heinrich MC, Druker BJ, Middleton PG, Deininger MW (2005) A single nucleotide polymorphism in the coding region of $\mathrm{ABL}$ and its effects on sensitivity to imatinib. Leukemia 19: 1859-1862

Cunningham JM, Sellers TA, Schildkraut JM, Fredericksen ZS, Vierkant RA, Kelemen LE, Gadre M, Phelan CM, Huang Y, Meyer JG, Pankratz VS, Goode EL (2008) Performance of amplified DNA in an Illumina GoldenGate BeadArray assay. Cancer Epidemiol Biomarkers Prev 17: $1781-1789$

D'Andrilli G, Kumar C, Scambia G, Giordano A (2004) Cell cycle genes in ovarian cancer: steps toward earlier diagnosis and novel therapies. Clin Cancer Res 10: $8132-8141$

De Keersmaecker K, Cools J (2006) Chronic myeloproliferative disorders: a tyrosine kinase tale. Leukemia 20: 200-205

De Meyer T, Bijsmans IT, Van de Vijver KK, Bekaert S, Oosting J, Van Criekinge W, van Engeland M, Sieben NL (2009) E2Fs mediate of Kathryn Sladek Smith for their generous support of the Ovarian Cancer Association Consortium through their donations to the Ovarian Cancer Research Fund. This work was supported in part by NIH grants CA 122443 and CA 88868 , as well as grant CA15083, which supports the Mayo Clinic College of Medicine Genotyping Shared Resource. Grant support: National Cancer Institute, grants R01 CA88868, R01 CA122443 and CA15083.

Supplementary Information accompanies the paper on British Journal of Cancer website (http://www.nature.com/bjc) a fundamental cell-cycle deregulation in high-grade serous ovarian carcinomas. J Pathol 217: 14-20

Dicioccio RA, Song H, Waterfall C, Kimura MT, Nagase H, McGuire V, Hogdall E, Shah MN, Luben RN, Easton DF, Jacobs IJ, Ponder BA, Whittemore AS, Gayther SA, Pharoah PD, Kruger-Kjaer S (2004) STK15 polymorphisms and association with risk of invasive ovarian cancer. Cancer Epidemiol Biomarkers Prev 13: 1589-1594

Dong LM, Potter JD, White E, Ulrich CM, Cardon LR, Peters U (2008) Genetic susceptibility to cancer: the role of polymorphisms in candidate genes. JAMA 299: 2423-2436

Elledge SJ (1996) Cell cycle checkpoints: preventing an identity crisis. Science (New York, NY) 274: 1664-1672

Frescas D, Pagano M (2008) Deregulated proteolysis by the F-box proteins SKP2 and beta-TrCP: tipping the scales of cancer. Nat Rev 8: 438-449

Gayther SA, Song H, Ramus SJ, Kjaer SK, Whittemore AS, Quaye L, Tyrer J, Shadforth D, Hogdall E, Hogdall C, Blaeker J, DiCioccio R, McGuire V, Webb PM, Beesley J, Green AC, Whiteman DC, Goodman MT, Lurie G, Carney ME, Modugno F, Ness RB, Edwards RP, Moysich KB, Goode EL, Couch FJ, Cunningham JM, Sellers TA, Wu AH, Pike MC, Iversen ES, Marks JR, Garcia-Closas M, Brinton L, Lissowska J, Peplonska B, Easton DF, Jacobs I, Ponder BA, Schildkraut J, Pearce CL, Chenevix-Trench G, Berchuck A, Pharoah PD (2007) Tagging single nucleotide polymorphisms in cell cycle control genes and susceptibility to invasive epithelial ovarian cancer. Cancer Res 67: 3027-3035

Goode EL, Fridley BL, Vierkant RA, Cunningham JM, Phelan CM, Anderson S, Rider DN, White KL, Pankratz VS, Song H, Hogdall E, Kjaer SK, Whittemore AS, Dicioccio R, Ramus SJ, Gayther SA, Schildkraut JM, Pharaoh PP, Sellers TA (2009) Candidate gene analysis using imputed genotypes: cell cycle single-nucleotide polymorphisms and ovarian cancer risk. Cancer Epidemiol Biomarkers Prev 18: 935-944

Hashiguchi Y, Tsuda H, Inoue T, Nishimura S, Suzuki T, Kawamura N (2004) Alteration of cell cycle regulators correlates with survival in epithelial ovarian cancer patients. Hum Pathol 35: 165-175

Ioannidis JP, Ntzani EE, Trikalinos TA, Contopoulos-Ioannidis DG (2001) Replication validity of genetic association studies. Nat Genet 29: 306-309

Kelemen LE, Sellers TA, Schildkraut JM, Cunningham JM, Vierkant RA, Pankratz VS, Fredericksen ZS, Gadre MK, Rider DN, Liebow M, Goode EL (2008) Genetic variation in the one-carbon transfer pathway and ovarian cancer risk. Cancer Res 68: 2498-2506

Kharbanda S, Ren R, Pandey P, Shafman TD, Feller SM, Weichselbaum RR, Kufe DW (1995) Activation of the c-Abl tyrosine kinase in the stress response to DNA-damaging agents. Nature 376: 785-788

Lancaster JM, Powell CB, Kauff ND, Cass I, Chen LM, Lu KH, Mutch DG, Berchuck A, Karlan BY, Herzog TJ (2007) Society of Gynecologic Oncologists Education Committee statement on risk assessment for inherited gynecologic cancer predispositions. Gynecol Oncol 107: 159-162

Lewis JM, Baskaran R, Taagepera S, Schwartz MA, Wang JY (1996) Integrin regulation of c-Abl tyrosine kinase activity and cytoplasmic-nuclear transport. Proc Natl Acad Sci USA 93: 15174-15179

Lin TY, Huang CH, Chou WG, Juang JL (2004) Abi enhances Abl-mediated CDC2 phosphorylation and inactivation. J Biomed Sci 11: 902-910

Mann A, Hogdall E, Ramus SJ, Dicioccio RA, Hogdall C, Quaye L, McGuire V, Whittemore AS, Shah M, Greenberg D, Easton DF, Ponder BA, Kjaer SK, Gayther SA, Thompson DJ, Pharoah PD, Song H (2008) Mismatch repair gene polymorphisms and survival in invasive ovarian cancer patients. Eur J Cancer 2008; 44(15): 2259-2265 
Milde-Langosch K, Riethdorf S (2003) Role of cell-cycle regulatory proteins in gynecological cancer. J Cell Physiol 196: 224-244

Morgan TM, Krumholz HM, Lifton RP, Spertus JA (2007) Nonvalidation of reported genetic risk factors for acute coronary syndrome in a large-scale replication study. JAMA 297: 1551-1561

Nam EJ, Kim YT (2008) Alteration of cell-cycle regulation in epithelial ovarian cancer. Int J Gynecol Cancer 2008; 18(6): 1169-1182

Parkin DM, Bray F, Ferlay J, Pisani P (2005) Global cancer statistics, 2002. CA Cancer J Clin 55: 74-108

Pearce CL, Wu AH, Gayther SA, Bale AE, Beck PA, Beesley J, Chanock S, Cramer DW, DiCioccio R, Edwards R, Fredericksen ZS, Garcia-Closas M, Goode EL, Green AC, Hartmann LC, Hogdall E, Kjaer SK, Lissowska J, McGuire V, Modugno F, Moysich K, Ness RB, Ramus SJ, Risch HA, Sellers TA, Song H, Stram DO, Terry KL, Webb PM, Whiteman DC, Whittemore AS, Zheng W, Pharoah PD, Chenevix-Trench G, Pike MC, Schildkraut J, Berchuck A (2008) Progesterone receptor variation and risk of ovarian cancer is limited to the invasive endometrioid subtype: results from the Ovarian Cancer Association Consortium pooled analysis. Br J Cancer 98: 282-288

Pharoah PD, Tyrer J, Dunning AM, Easton DF, Ponder BA (2007) Association between common variation in 120 candidate genes and breast cancer risk. PLoS Genetics 3: e42

Preyer M, Shu CW, Wang JY (2007) Delayed activation of Bax by DNA damage in embryonic stem cells with knock-in mutations of the Abl nuclear localization signals. Cell Death Differ 14: 1139-1148

Quaye L, Gayther SA, Ramus SJ, Di Cioccio RA, McGuire V, Hogdall E, Hogdall C, Blaakr J, Easton DF, Ponder BA, Jacobs I, Kjaer SK, Whittemore AS, Pearce CL, Pharoah PD, Song H (2008) The effects of common genetic variants in oncogenes on ovarian cancer survival. Clin Cancer Res 14: 5833-5839

Ramus SJ, Vierkant RA, Johnatty SE, Pike MC, Van Den Berg DJ, Wu AH, Pearce CL, Menon U, Gentry-Maharaj A, Gayther SA, Dicioccio RA, McGuire V, Whittemore AS, Song H, Easton DF, Pharoah PD, Garcia-Closas M, Chanock S, Lissowska J, Brinton L, Terry KL, Cramer DW, Tworoger SS, Hankinson SE, Berchuck A, Moorman PG,
Schildkraut JM, Cunningham JM, Liebow M, Kjaer SK, Hogdall E, Hogdall C, Blaakaer J, Ness RB, Moysich KB, Edwards RP, Carney ME, Lurie G, Goodman MT, Wang-Gohrke S, Kropp S, Chang-Claude J, Webb PM, Chen X, Beesley J, Chenevix-Trench G, Goode EL (2008) Consortium analysis of 7 candidate SNPs for ovarian cancer. Int $J$ Cancer 123: $380-388$

Sellers TA, Huang Y, Cunningham J, Goode EL, Sutphen R, Vierkant RA, Kelemen LE, Fredericksen ZS, Liebow M, Pankratz VS, Hartmann LC, Myer J, Iversen Jr ES, Schildkraut JM, Phelan C (2008) Association of single nucleotide polymorphisms in glycosylation genes with risk of epithelial ovarian cancer. Cancer Epidemiol Biomarkers Prev 17: $397-404$

Sellers TA, Schildkraut JM, Pankratz VS, Vierkant RA, Fredericksen ZS, Olson JE, Cunningham J, Taylor W, Liebow M, McPherson C, Hartmann LC, Pal T, Adjei AA (2005) Estrogen bioactivation, genetic polymorphisms, and ovarian cancer. Cancer Epidemiol Biomarkers Prev 14: $2536-2543$

Song H, Ramus SJ, Kjaer SK, Hogdall E, Dicioccio RA, Whittemore AS, McGuire V, Hogdall C, Jacobs IJ, Easton DF, Ponder BA, Dunning AM, Gayther SA, Pharoah PD (2007) Tagging single nucleotide polymorphisms in the BRIP1 gene and susceptibility to breast and ovarian cancer. PLOS ONE 2: e268

Wang JYJ (1993) Abl tyrosine kinase in signal transduction and cell-cycle regulation. Curr Opin Gen Dev 3: 35-43

Weir B (1996) Genetic Data Anlaysis II: Methods for Discrete Population Genetic Data. Sinauer Associates, Inc: Sunderland, MA

Welch PJ, Wang JY (1993) A C-terminal protein-binding domain in the retinoblastoma protein regulates nuclear $\mathrm{c}$-Abl tyrosine kinase in the cell cycle. Cell 75: 779-790

Woodring PJ, Hunter T, Wang JY (2003) Regulation of F-actin-dependent processes by the Abl family of tyrosine kinases. J Cell Sci 116: 2613-2626

Yuan J, Eckerdt F, Bereiter-Hahn J, Kurunci-Csacsko E, Kaufmann M, Strebhardt K (2002) Cooperative phosphorylation including the activity of polo-like kinase 1 regulates the subcellular localization of cyclin B1. Oncogene 21: $8282-8292$ 